\title{
Biosynthesis and Lipase-Catalysed Hydrolysis of 4-Hydroxybutyrate-Containing Polyhydroxyalkanoates from Delftia acidovorans
}

\author{
Diana Hooi-Ean Ch'ng, Wing-Hin Lee and Kumar Sudesh*
}

\author{
School of Biological Sciences, Universiti Sains Malaysia. 11800 Penang, Malaysia \\ E.mail: ksudesh@usm.my
}

Received 27 March 2012; Received in revised form 3 April 2012; Accepted 6 April 2012

\begin{abstract}
Aims: Polyhydroxyalkanoates (PHA) having various molar fractions of 4-hydroxybutyrate has been successfully synthesized by Delftia acidovorans.

Methodology and results: The monomer compositions of the PHA were varied by cultivating the bacterium in a mixture of 1,4-butanediol and sodium valerate, $y$-butyrolactone and sodium valerate as well as 4-hydroxybutyric acid and sodium valerate, which resulted in the production of PHA terpolymers. Although the highest terpolymer content achieved was only $57 \mathrm{wt} \%$ of the dry cell weight, the $4 \mathrm{HB}$ molar fractions can be regulated from $2-50 \mathrm{~mol} \%$ when culture conditions such as initial $\mathrm{pH}$, inoculum concentration and aeration were varied. The in vitro degradation of $[\mathrm{P}(3 \mathrm{HB}-\mathrm{co}-50 \% 4 \mathrm{HB})]$ synthesized by $D$. acidovorans were also studied by monitoring the erosion rate of the copolymer in aqueous solutions of lipases (Lipase A 'Amano' 12 and Newlase F). Results have shown that the types of lipases, concentration of lipase solution and $\mathrm{pH}$ of the buffer solution influenced the degradation rate of the PHA copolymer.

Conclusion, significance and impact of the study: The overall results have shown that $D$. acidovorans is a very promising strain for the production of $4 \mathrm{HB}$ containing PHAs with specific compositions which are very suitable to be tailor made into biodegradable and biocompatible materials for medical applications.
\end{abstract}

Keywords: polyhydroxyalkanoate, terpolymer, 4-hydroxybutyrate, 3-hydroxyvalerate, Delftia acidovorans

\section{INTRODUCTION}

Polyhydroxyalkanoates (PHAs) are microbial polyesters with many potential applications. PHAs that contain 4hydroxybutyrate $(4 \mathrm{HB})$ monomer are especially interesting as bioabsorbable materials for applications in medical devices (Martin and Williams 2003). Biocompatibility is an important factor that determines the applicability of any material in medical devices. Although PHA is generally accepted as a biocompatible material, the source of this polymer is mainly gram-negative bacteria, which contains endotoxins. Various extraction and purification methods have been reported to remove endotoxins from PHA (Zinn et al. 2007).

Among the various wild-type microorganisms that have the ability to synthesize PHA that contains 4HB, Delftia acidovorans has been shown to have the most efficient metabolic pathways for the production of poly (4hydroxybutyrate) $[\mathrm{P}(4 \mathrm{HB})]$ homopolymer and poly(3hydroxybutyrate-co-4-hydroxybutyrate) [P(3HB-co-4HB)] copolymer (Saito and Doi 1994). In previous studies (Siew et al. 2007; Siew et al. 2009; Ying et al. 2008) we have found that PHAs extracted from $D$. acidovorans were generally safe based on cytotoxicity, genotoxicity and implant tests. Therefore, $D$. acidovorans is a potential strain for the production of PHAs for medical applications. One of the greatest challenges in the biosynthesis of
PHAs for various applications is the ability to control the monomer compositions in a wide range. It is known that the properties of PHA are dependent on the type and molar ratios of different monomers. While $3 \mathrm{HB}$ and $3 \mathrm{HV}$ monomers contribute to the stiffness and strength of PHAs (Holmes 1985), 4HB monomer resulted in their flexibility and elasticity (Saito et al. 1996). In addition, 4HB monomers enabled the PHA to be hydrolyzed by lipases (Jaeger et al. 1995), which makes the PHA attractive as an absorbable biomaterial. The biosynthesis of $\mathrm{P}(3 \mathrm{HB}-\mathrm{co}-$ $4 \mathrm{HB}$ ) and poly(3-hydroxybutyrate-co-3-hydroxyvalerate) [P(3HB-co-3HV)] with controlled composition by $D$. acidovorans have been reported. However, not much is known about the strategy to produce poly(3hydroxybutyrate-co-4-hydroxybutyrate-co-3-hydroxyvalerate) [P(3HB-co-3HV-co-4HB)] terpolymer by $D$. acidovorans with precise molar fractions.

The discovery of the ability of $D$. acidovorans to produce $\mathrm{P}(3 \mathrm{HB}-\mathrm{co}-4 \mathrm{HB}-\mathrm{co}-3 \mathrm{HV}$ ) dates back to 1992 (Kimura et al. 1992). However, $4 \mathrm{HB}$ was the major constituent monomer in the terpolymer chain (44-88 \%) and the increase of $3 \mathrm{HV}$ monomers hampered the overall PHA accumulating ability of the strain. Recent developments of the production of $\mathrm{P}(3 \mathrm{HB}-\mathrm{co}-3 \mathrm{HV}-\mathrm{co}-4 \mathrm{HB})$ terpolymer by other bacterial strains (Amirul et al. 2008; Chanprateep and Kulpreecha2006; Ramachandran et al. 2011) have suggested the possibility of improving the production and compositions of the terpolymer by $D$. acidovorans. 
Table 1: Effect of sodium valerate concentration on the biosynthesis of $\mathrm{P}(3 \mathrm{HB}-\mathrm{co}-3 \mathrm{HV}-\mathrm{co}-4 \mathrm{HB})$ by $D$. acidovorans ${ }^{\mathrm{a}}$

\begin{tabular}{|c|c|c|c|c|c|c|c|}
\hline \multicolumn{3}{|c|}{ Carbon source } & \multirow{2}{*}{$\begin{array}{l}\text { Dry cell weight } \\
(\mathrm{g} / \mathrm{L})\end{array}$} & \multirow[t]{2}{*}{ PHA content ${ }^{\mathrm{D}}(\mathrm{wt} \%)$} & \multicolumn{3}{|c|}{ PHA composition (mol \%) } \\
\hline $\begin{array}{l}\text { 1,4-BD } \\
\text { (w/v) }\end{array}$ & $\begin{array}{c}\text { Glu } \\
(w / v)\end{array}$ & $\begin{array}{l}\text { S.Val } \\
(w / v)\end{array}$ & & & $3 \mathrm{HB}$ & $3 \mathrm{HV}$ & $4 \mathrm{HB}$ \\
\hline 0.5 & 0.5 & 0.1 & 2.3 & 32 & 87 & 8 & 5 \\
\hline 0.5 & 0.5 & 0.2 & 2.4 & 36 & 86 & 13 & 1 \\
\hline 0.5 & 0.5 & 0.3 & 2.4 & 40 & 79 & 16 & 5 \\
\hline 0.5 & 0.5 & 0.4 & 2.6 & 42 & 78 & 17 & 5 \\
\hline 0.5 & 0.5 & 0.5 & 2.4 & 47 & 76 & 20 & 4 \\
\hline 0.5 & 0.5 & 0.6 & 2.6 & 46 & 75 & 20 & 5 \\
\hline 0.5 & 0.5 & 0.7 & 2.6 & 57 & 75 & 20 & 5 \\
\hline 0.5 & 0.5 & 0.8 & 2.6 & 24 & 66 & 29 & 5 \\
\hline 0.5 & 0.5 & 0.9 & 2.6 & 20 & 70 & 26 & 4 \\
\hline 0.5 & 0.5 & 1.0 & 2.4 & 16 & 74 & 21 & 5 \\
\hline
\end{tabular}

1,4-BD, 1,4-butanediol; Glu, glucose; S.Val, sodium valerate; 3HB, 3-hydroxybutyrate;

3-HV, 3-hydroxyvalerate; 4HB, 4-hydroxybutyrate.

${ }^{a}$ Incubated for $48 \mathrm{~h}$ at $30^{\circ} \mathrm{C}$, initial $\mathrm{pH} 7.0$.

${ }^{b}$ PHA content in dry cells.

As such, the main focus of this study was to evaluate the ability of $D$. acidovorans to produce $\mathrm{P}(3 \mathrm{HB}-\mathrm{co}-3 \mathrm{HV}-\mathrm{co}-$ $4 \mathrm{HB})$ with various monomer compositions. The concentrations of carbon sources were varied and different culture conditions were applied to study their effect on the incorporation of $3 \mathrm{HV}$ and $4 \mathrm{HB}$ monomers. Besides, P(3HB-co-50 mol\%-4HB) copolymer which was successfully produced in our previous studies by $D$. acidovorans (Lee et al. 2004) was used to study the effect of two types of commercial lipases, their concentrations and $\mathrm{pH}$ on the in vitro degradation of the polymer.

\section{MATERIALS AND METHODS}

\section{Biosynthesis of $\mathrm{P}(3 \mathrm{HB}-\mathrm{co}-3 \mathrm{HV}-\mathrm{co}-4 \mathrm{HB})$ terpolymers}

D. acidovorans JCM 10181 was cultivated and maintained as previously described (Lee et al. 2004). Two- step cultivation was practiced by using $D$. acidovorans for the biosynthesis of terpolymer. For the first stage of cultivation, $3 \%(\mathrm{vol} / \mathrm{vol})$ of fresh culture was inoculated into $100 \mathrm{~mL}$ NB medium ( $\mathrm{pH} 7.0)$ with $1 \%$ (wt/vol) glucose in a $500 \mathrm{~mL}$ flask. After $24 \mathrm{~h}$, the cells were recovered by centrifugation at $4000 \mathrm{~g}, 16^{\circ} \mathrm{C}$ for $10 \mathrm{~min}$. To promote synthesis of PHA, the centrifuged cells were transferred into the second stage medium which consisted of a $100 \mathrm{~mL}$ nitrogen free medium $(\mathrm{pH} 7.0)$. Carbon sources such as glucose, 1,4-butanediol (1,4-BD), sodium 4-hydroxybutyrate (S4HB), $\mathrm{Y}$-butyrolactone ( $\mathrm{Y}$-BL) and sodium valerate were autoclaved separately and added aseptically to the medium to promote synthesis of $\mathrm{P}(3 \mathrm{HB}$ co-3HV-co-4HB) terpolymers.

\section{Preparation of sodium valerate and sodium 4- hydroxybutyrate}

Sodium valerate was prepared by mixing valeric acid with

$\mathrm{NaOH}$ solution. $1 \mathrm{M}$ of $\mathrm{NaOH}$ solution was prepared by dissolving $40 \mathrm{~g}$ of $\mathrm{NaOH}$ in $1 \mathrm{~L}$ of $(95 \%)$ ethanol. Then, approximately $102 \mathrm{~mL}$ of valeric acid was poured into the
$\mathrm{NaOH}$ solution. The sodium valerate precipitate that was formed was recovered and dried in an oven at $45{ }^{\circ} \mathrm{C}$ to constant weight. The sodium valerate was used as the $3 \mathrm{HV}$ precursor carbon source. The sodium salt of 4hydroxybutyrate was produced by the reaction of $\mathrm{Y}$ butyrolactone with $\mathrm{NaOH}$ solution. A total of $60 \mathrm{~g} \mathrm{NaOH}$ was stirred in $1 \mathrm{~L}$ of absolute ethanol until complete dissolution. Approximately $120 \mathrm{~mL}$ y-butyrolactone was poured into the $\mathrm{NaOH}$ solution. The precipitated sodium salt of 4-hydroxybutyrate was placed in $45^{\circ} \mathrm{C}$ oven until constant weight. After the drying process, the S4HB was kept in an airtight bag for further use.

\section{Analytical procedures}

At the end of second-stage cultivation (48 h), bacterial cells were collected by centrifugation and subjected to lyophilization. In order to determine PHA content and composition, approximately $25 \mathrm{mg}$ of lyophilized cells was subjected to methanolysis with $2 \mathrm{~mL}$ of chloroform and 2 $\mathrm{mL}$ of methanolysis solution $[85 \%(\mathrm{vol} / \mathrm{vol})$ methanol and $15 \%$ (vol/vol) sulphuric acid] at $100{ }^{\circ} \mathrm{C}$ for $140 \mathrm{~min}$. The resulting hydroxyacyl methyl esters were analyzed by gas chromatography according to well-established method (Braunegg et al. 1978).

\section{Enzymatic degradation of $\mathrm{P}(3 \mathrm{HB}-\mathrm{co}-50 \mathrm{~mol} \%-4 \mathrm{HB})$}

Lipase A "Amano" 12 from Aspergillus niger and Newlase $\mathrm{F}$ from Rhizopus niveus (both from Amano Enzymes Inc, Japan) were used in this study. $\mathrm{P}$ (3HB-co-50 mol\%-4HB) was biosynthesized as described previously by Lee and coworkers with the addition of glucose and 1,4-butanediol in the second stage medium as carbon sources. Lipase solutions of Lipase $A$ and Newlase $F$ with 4 different concentrations ( $5 \mathrm{U}, 50 \mathrm{U}, 500 \mathrm{U}$ and $5000 \mathrm{U}$ ) each were prepared by dissolving the appropriate amount of lipase powder in $0.1 \mathrm{M}$ phosphate buffer according to the information supplied by Amano Enzymes Inc, Japan. Two sets of experiments were conducted whereby phosphate buffer of $\mathrm{pH} 5$ and $\mathrm{pH} 7$ were used to dissolve each of the lipases. 14 pieces of $1 \mathrm{~cm}^{2}$ cast films of $\mathrm{P}(3 \mathrm{HB}-\mathrm{co}-50$ 
mol\%-4HB) (initial weight of about $0.5 \mathrm{mg} \pm 0.1 \mathrm{mg}$ ) were added into each flask with $100 \mathrm{~mL}$ phosphate buffer. All flasks were incubated in a rotating shaker (CERTOMAT $\mathrm{R})$ at $200 \mathrm{rpm}$ and $37{ }^{\circ} \mathrm{C}$. 2 sample films were removed every $24 \mathrm{~h}$ from each flask, washed with distilled water and dried in incubator $\left(37^{\circ} \mathrm{C}\right)$ for $24 \mathrm{~h}$ before being weighed. The weight loss of the films was recorded throughout a period of 7 days.

\section{RESULTS AND DISCUSSION}

Effect of sodium valerate concentration on $\mathrm{P}(3 \mathrm{HB}-\mathrm{co}$ $3 \mathrm{HV}-\mathrm{co}-4 \mathrm{HB}$ ) terpolymer content and composition

Sodium valerate was used as the precursor for $3 \mathrm{HV}$ monomer in the biosynthesis of $\mathrm{P}(3 \mathrm{HB}-\mathrm{co}-3 \mathrm{HV}-\mathrm{co}-4 \mathrm{HB})$ terpolymer in this study. It was not possible to use sodium propionate as $3 \mathrm{HV}$ precursors since it displayed toxicity to the bacterial cells and contributed to subsequent reduction of terpolymer production (results not shown). Previous reports have revealed that the addition of glucose during cultivation significantly boosted the PHA accumulating capacity of bacteria as it induces certain enzymes that are involved in the generation of acetyl-CoA (Taidi et al. 1994; Lee et al. 2004). Therefore, the combination of $1,4-\mathrm{BD}$, glucose and sodium valerate was used to study the effect of sodium valerate concentration on the biosynthesis of $\mathrm{P}(3 \mathrm{HB}-\mathrm{co}-3 \mathrm{HV}-\mathrm{Co}-4 \mathrm{HB})$. Table 1 shows the effect of sodium valerate concentration on $\mathrm{P}(3 \mathrm{HB}-\mathrm{co}-3 \mathrm{HV}-\mathrm{co}-4 \mathrm{HB})$ terpolymer content and composition synthesized by $D$. acidovorans. The combination of three carbon sources resulted in terpolymer containing $8-29 \mathrm{~mol} \%$ 3HV monomers, whereas the $3 \mathrm{HB}$ and $4 \mathrm{HB}$ monomers were almost unaffected and remained at approximately $80 \mathrm{~mol} \%$ and 5 $\mathrm{mol} \%$ respectively regardless of the concentrations of sodium valerate. Although a highest terpolymer content of $57 \mathrm{wt} \%$ was achieved, the addition of glucose had a negative impact on the study.

The addition of glucose in the medium has rendered the cells to favor the accumulation of $3 \mathrm{HB}$, whereby the $3 \mathrm{HB}$ monomer composition constantly maintained at a much higher percentage if compared to the other two monomers. The pathway to biosynthesize $3 \mathrm{HB}$ by glucose (TCA cycle) was clearly preferred by the bacterium to the extent that the increase in the amount of $3 \mathrm{HV}$ precursors has little effect on the monomer composition of $3 \mathrm{HV}$ in the resulting terpolymer. Addition of glucose into the secondstage medium has significantly enhanced $3 \mathrm{HB}$ monomer composition. A similar observation was made by Madden et al. (2000) when glucose, propionic acid and $\mathrm{y}-\mathrm{BL}$ were fed into the medium. Besides, the accumulation of $4 \mathrm{HB}$ monomer was only around $5 \mathrm{~mol} \%$. Since it was concluded that the addition of glucose will be suitable only for the production of $\mathrm{P}(3 \mathrm{HB}-\mathrm{co}-3 \mathrm{HV}-\mathrm{CO}-4 \mathrm{HB})$ terpolymer with low $3 \mathrm{HV}$ and $4 \mathrm{HB}$ monomer compositions, glucose should be eliminated from the list of carbon sources for the production of $\mathrm{P}(3 \mathrm{HB}-\mathrm{Co}-3 \mathrm{HV}-\mathrm{co}-4 \mathrm{HB})$ terpolymer with wider range of compositions.

\section{Production of $P(3 H B-c o-3 H V-c o-4 H B)$ terpolymer with a wide range of monomer composition}

The next attempt to synthesize $\mathrm{P}(3 \mathrm{HB}-\mathrm{co}-3 \mathrm{HV}-\mathrm{co}-4 \mathrm{HB})$ with a wide range of $4 \mathrm{HB}$ and $3 \mathrm{HV}$ monomers was by studying the effect of combinations of two carbon sources which are responsible for the generation of each of the respective monomers. $D$. acidovorans was cultured together with the combination of three different types of $4 \mathrm{HB}$ structurally related carbon sources $(1,4-B D, y-B L$ or $4 \mathrm{HBA}$ ) and sodium valerate to observe the resulting compositions and amount of terpolymer produced. The removal of glucose from the list of carbon feedstock successfully limited the channeling of excess acetyl-CoA that was generated mainly from glucose to the formation of $3 \mathrm{HB}$ monomers. The combination of $1,4-\mathrm{BD}$ or $4 \mathrm{HBA}$ with sodium valerate enabled the control of $3 \mathrm{HV}$ and $4 \mathrm{HB}$ monomer compositions when the concentrations of both the monomer precursors was adjusted accordingly, as shown in Table 2.

Table 2: Biosynthesis of $\mathrm{P}(3 \mathrm{HB}-\mathrm{co}-3 \mathrm{HV}-\mathrm{co}-4 \mathrm{HB})$ containing different $3 \mathrm{HV}$ and $4 \mathrm{HB}$ compositions from different carbon sources in various concentrations ${ }^{a}$

\begin{tabular}{|c|c|c|c|c|c|c|}
\hline \multicolumn{2}{|c|}{ Carbon source } & \multirow{2}{*}{$\begin{array}{l}\text { Dry } \\
\text { cell } \\
\text { weight } \\
(\mathrm{g} / \mathrm{L})\end{array}$} & \multirow{2}{*}{$\begin{array}{l}\text { PHA } \\
\text { content }^{b} \\
\text { (wt } \%)\end{array}$} & \multicolumn{3}{|c|}{$\begin{array}{l}\text { PHA composition } \\
(\mathrm{mol} \%)\end{array}$} \\
\hline $\begin{array}{l}\text { 1,4-BD } \\
\text { (vol/vol) }\end{array}$ & $\begin{array}{l}\text { S. Val } \\
\text { (wt/vol) }\end{array}$ & & & $3 \mathrm{HB}$ & $3 \mathrm{HV}$ & $4 \mathrm{HB}$ \\
\hline 1.0 & 0 & 2.6 & 23 & 16 & 0 & 84 \\
\hline 0.8 & 0.2 & 2.9 & 24 & 39 & 27 & 24 \\
\hline 0.6 & 0.4 & 2.5 & 33 & 58 & 35 & 7 \\
\hline 0.4 & 0.6 & 2.4 & 50 & 49 & 43 & 8 \\
\hline 0.2 & 0.8 & 2.5 & 28 & 34 & 64 & 2 \\
\hline 0 & 1.0 & 2.5 & 22 & 12 & 88 & 0 \\
\hline $\begin{array}{l}\mathrm{Y}-\mathrm{BL} \\
\text { ( } \mathrm{vol} / \mathrm{vol})\end{array}$ & $\begin{array}{l}\text { S.Val } \\
\text { (wt/vol) }\end{array}$ & & & & & \\
\hline 1.0 & 0 & 2.2 & 6 & 46 & 0 & 54 \\
\hline 0.8 & 0.2 & 2.5 & 31 & 39 & 54 & 7 \\
\hline 0.6 & 0.4 & 2.5 & 23 & 37 & 55 & 8 \\
\hline 0.4 & 0.6 & 2.4 & 44 & 47 & 45 & 8 \\
\hline 0.2 & 0.8 & 2.6 & 48 & 42 & 52 & 6 \\
\hline 0 & 1.0 & 2.5 & 22 & 12 & 88 & 0 \\
\hline $\begin{array}{l}\text { S4HB } \\
\text { ( } \mathrm{vol} / \mathrm{vol} \text { ) }\end{array}$ & $\begin{array}{l}\text { S.Val } \\
\text { (wt/vol) }\end{array}$ & & & & & \\
\hline 1.0 & 0 & 2.5 & 25 & 4 & 0 & 96 \\
\hline 0.8 & 0.2 & 2.5 & 22 & 25 & 35 & 40 \\
\hline 0.6 & 0.4 & 2.6 & 28 & 36 & 51 & 13 \\
\hline 0.4 & 0.6 & 2.6 & 43 & 23 & 71 & 6 \\
\hline 0.2 & 0.8 & 2.5 & 36 & 10 & 86 & 4 \\
\hline 0 & 1.0 & 2.5 & 22 & 12 & 88 & 0 \\
\hline
\end{tabular}

1,4-BD, 1,4-butanediol; $\mathrm{Y}$-BL, $\mathrm{Y}$-butyrolactone; S4HB, Sodium 4-hydroxybutyrate; S.Val,

sodium valerate; 3HB, 3-hydroxybutyrate; 3-HV, 3hydroxyvalerate; $4 \mathrm{HB}, 4$-hydroxybutyrate.

a Incubated for $48 \mathrm{~h}$ at $30^{\circ} \mathrm{C}$, initial $\mathrm{pH} 7.0$.

${ }^{b}$ PHA content in dry cells.

The combination of 1,4- $\mathrm{BD}$ with sodium valerate resulted in the biosynthesis of $\mathrm{P}(3 \mathrm{HB}-\mathrm{CO}-3 \mathrm{HV}-\mathrm{co}-4 \mathrm{HB})$ containing the widest range of $3 \mathrm{HV}$ monomer composition (27-88 
mol\%) as well as the highest amount of PHA content (50 wt $\%)$. The combination of $4 \mathrm{HBA}$ with sodium valerate also produced a comparable trend in $3 \mathrm{HV}$ monomer composition with the highest $4 \mathrm{HB}$ monomer composition of $40 \%$ in the terpolymer. However, the monomer composition of $3 \mathrm{HV}$ remained constant at around $50 \mathrm{~mol} \%$ when $\mathrm{Y}-\mathrm{BL}$ was used together with sodium valerate as carbon sources. The observation may result from the poorer ability of $\mathrm{Y}-\mathrm{BL}$ to be incorporated as $4 \mathrm{HB}$ monomers ( $54 \mathrm{~mol} \%$ of $4 \mathrm{HB}$ when used as sole carbon source) if compared to 1,4-butanediol (84 mol\% of $4 \mathrm{HB}$ when used as sole carbon source) or $4 \mathrm{HBA}$ (96 mol\% of $4 \mathrm{HB}$ when used as sole carbon source). This suggested that $y$-butyrolactone was not a suitable carbon source to be used for the production of $\mathrm{P}(3 \mathrm{HB}-\mathrm{co}-3 \mathrm{HV}-\mathrm{co}-4 \mathrm{HB})$ with controlled compositions. According to the results obtained in this study, the increase in the composition of $3 \mathrm{HV}$ simultaneously suppressed the accumulation of $4 \mathrm{HB}$ monomers, whereby the monomer composition of $4 \mathrm{HB}$ was seen to decrease drastically together with the accumulation of $3 \mathrm{HV}$ monomers. The presence of sodium valerate has a very negative impact on the accumulation of $4 \mathrm{HB}$.

The 4HB monomer compositions dropped drastically even when only $0.2 \%$ of sodium valerate was used. Fortunately, only a low amount of sodium valerate was needed to obtain a significant accumulation of 3HV monomers. Therefore, the amount of sodium valerate to be used in the subsequent experiment was adjusted to minimize its $4 \mathrm{HB}$ inhibiting effect in order to produce a terpolymer with a higher composition of $4 \mathrm{HB}$ monomers. Although the combination of $4 \mathrm{HBA}$ and sodium valerate has the advantage of generating a terpolymer with a higher $4 \mathrm{HB}$ or $3 \mathrm{HV}$ composition ( 40 and $86 \%$ respectively), the availability and lower pricing of 1,4-BD in the market might make it a better choice as one ofthe raw material for the mass production of the terpolymer. The choice of carbon sources to use will also depend on the application of the final product.

Table 3: Effect of initial $\mathrm{pH}$ on the biosynthesis of $\mathrm{P}(3 \mathrm{HB}$ co-3HV-co- $4 \mathrm{HB})$ by using $0.1 \%(\mathrm{wt} / \mathrm{vol})$ sodium valerate and $0.9 \%(\mathrm{vol} / \mathrm{vol}) 1,4-$ butanediol $^{\mathrm{a}}$

\begin{tabular}{cccrrr}
\hline \multirow{2}{*}{$\begin{array}{l}\text { DH } \\
\text { Dry cell } \\
\text { weight }(\mathrm{g} / \mathrm{L})\end{array}$} & $\begin{array}{l}\text { PHA content } \\
(\mathrm{wt} \%)\end{array}$ & \multicolumn{3}{l}{$\begin{array}{l}\text { PHA composition } \\
(\mathrm{mol} \%)\end{array}$} \\
\cline { 4 - 6 } & & & $3 \mathrm{HB}$ & $3 \mathrm{HV}$ & $4 \mathrm{HB}$ \\
\hline 5.0 & 2.0 & 10 & 32 & 29 & 39 \\
5.5 & 2.1 & 11 & 38 & 25 & 37 \\
6.0 & 2.3 & 21 & 42 & 23 & 35 \\
6.5 & 2.4 & 25 & 50 & 20 & 30 \\
7.0 & 2.5 & 31 & 32 & 35 & 33 \\
7.5 & 2.4 & 29 & 20 & 40 & 40 \\
8.0 & 2.6 & 28 & 10 & 43 & 47 \\
8.5 & 2.6 & 26 & 4 & 46 & 50
\end{tabular}

3HB, 3-hydroxybutyrate; 3-HV, 3-hydroxyvalerate; 4HB, 4hydroxybutyrate.

a Incubated for $48 \mathrm{~h}$ at $30^{\circ} \mathrm{C}$, initial $\mathrm{pH}$ 7.0.

${ }^{b}$ PHA content in dry cells.
Effect of initial $\mathrm{pH}$ on the $\mathrm{P}(3 \mathrm{HB}-\mathrm{co}-3 \mathrm{HV}-\mathrm{co}-4 \mathrm{HB})$ terpolymer content and composition

Besides regulating the concentrations of carbon sources to control the monomer compositions of PHA, other culture conditions will also determine the end result of the biosynthesis. $\mathrm{pH}$ is an important feature that one has to take into consideration especially when the end products are directly affected by $\mathrm{pH}$ variation. It was previously reported that the monomer composition of $\mathrm{P}(3 \mathrm{HB}-\mathrm{co}-4 \mathrm{HB})$ could be regulated by varying the initial $\mathrm{pH}$ of the culture medium (Lee et al. 2004). Therefore, this parameter was applied in this study to investigate the effect of $\mathrm{pH}$ on $\mathrm{P}(3 \mathrm{HB}-\mathrm{co}-3 \mathrm{HV}-\mathrm{co}-4 \mathrm{HB})$ monomer composition. Here we report, by changing the initial $\mathrm{pH}$ of the second-stage medium, significant effect was observed on the PHA composition of the terpolymer produced. A mixture of 0.1 $\%$ (wt/vol) sodium valerate and $0.9 \%$ (wt/vol) $1,4-B D$ were used as carbon sources. The PHA content and monomer composition were analyzed and listed in Table 3 . Results indicated that $\mathrm{pH}$ acted as a balance to level the monomer composition between $3 \mathrm{HB}$ versus $3 \mathrm{HV}$ and $4 \mathrm{HB}$. For instance, at a slightly acidic $\mathrm{pH}$ of $6.5,3 \mathrm{HB}$ accumulation was at the optimum point $(50 \mathrm{~mol} \%)$, and this subsequently brought about the lowest monomer composition of $4 \mathrm{HB}(30 \mathrm{~mol} \%)$ and $3 \mathrm{HV}(20 \mathrm{~mol} \%)$. Most probably, the production of acetyl-CoA was affected when the initial $\mathrm{pH}$ of the culture medium was changed. In contrast, at an alkaline $\mathrm{pH}$ of $8.5,3 \mathrm{HB}$ mol\% was much lowered (4 mol\%), and the monomer composition of $4 \mathrm{HB}$ and $3 \mathrm{HV}$ increased to 50 and $46 \mathrm{~mol} \%$ respectively. $\mathrm{A} \mathrm{pH}$ below 6 resulted in a much lowered PHA accumulation. This phenomenon showed that the PHA accumulating process is very sensitive to $\mathrm{pH}$ change and a $\mathrm{pH}$ of 6 and above is favorable for PHA production by $D$. acidovorans. The fact that it is possible to control the monomer composition of the terpolymer produced without much affecting the total PHA content by the manipulation of culture $\mathrm{pH}$ was interesting. A neutral $\mathrm{pH}$ balances the weight of each monomer whereas at an alkaline $\mathrm{pH}$, the accumulation of $3 \mathrm{HB}$ was much lowered and therefore a terpolymer with improved composition of both $3 \mathrm{HV}$ and $4 \mathrm{HB}$ has been achieved. In the year 2007, Loo and Sudesh reported that when sodium valerate was used as sole carbon source for PHA production in $D$. acidovorans, $\mathrm{pH}$ had little effect on the $3 \mathrm{HV}$ monomer composition of the PHA produced. However, in this study it was found that when 1,4-BD was added together as carbon feed stock, the molar fractions of the terpolymer produced can be controlled by $\mathrm{pH}$ changes.

Effect of inoculum concentration on the P(3HB-co$3 H V-c o-4 H B)$ terpolymer content and composition

Nutrient limitation is one of the key factors that are responsible in stimulating PHA producers to stock up on the biopolymer. Therefore, two-stage cultivation was applied on $D$. acidovorans to biosynthesize $\mathrm{P}(3 \mathrm{HB}-\mathrm{Co}-$ $3 \mathrm{HV}-\mathrm{co}-4 \mathrm{HB})$. Recent study had shown that inoculum concentrations for the first stage culture would have an 
effect on the PHA polymerization process in the bacterial cells. The concentrations of inoculum that was inoculated into the first stage culture medium would directly affect the time for the cells to reach stationary phase; therefore cultures with different inoculum concentrations were harvested at different period before being inoculated into the nitrogen-free second stage medium (Lee et al. 2004). Table 4 shows the effect of inoculum concentration on the ability of PHA accumulation by the bacterium and the monomer compositions of the terpolymer. Significant impact can be observed when the inoculum concentrations were merely increased from 1 to $3 \%$. Although the total PHA content had increased to $31 \%$ at 3 $\%$ of inoculum concentration, the 3HB monomer composition has clearly decreased from $57 \%$ to $32 \%$. $4 \mathrm{HB}$ on the other hand was positively affected with increase of monomer composition from 11 to $33 \%$. Interestingly, the monomer composition of $3 \mathrm{HV}$ was not affected by the concentration of inoculum. Generally, PHA producing bacteria can be divided into non-growth and growth associated PHA producers. D. acidovorans is a type of non-growth associated PHA producer; therefore two-stage cultivation is favorable for its production of PHA. Although much work has been done on PHA accumulation by two-stage cultivation, the question of the effect on the physiological state of cells when transferred into secondstage medium is still unanswered. Cultures started with different inoculum concentrations may need different time to reach stationary phase. It should be noted that all cultures were transferred into second-stage when they have reached the stationary phase. Therefore, a culture started from a higher inoculum concentration will have a younger cell population that has only multiplied several times before being transferred. These young cells have a better ability to incorporate $4 \mathrm{HB}$ monomer. It resulted in the $\mathrm{P}(3 \mathrm{HB}-\mathrm{co}-3 \mathrm{HV}-\mathrm{co}-4 \mathrm{HB})$ terpolymer having a high molar fraction ( $40 \mathrm{~mol} \%$ ) of $4 \mathrm{HB}$ monomer in the second stage. On the other hand, old cell populations are able to accumulate a high $3 \mathrm{HB}$ monomer composition in the terpolymer. The role of $\beta$-ketothiolase enzymes in the production of $\mathrm{P}(3 \mathrm{HB})$ has been demonstrated recently (Lindenkamp et al. 2010) and there may be a difference in the concentration of these enzymes in younger and older cells. It is however curious that the age of cells has no effect on the overall accumulation of $3 \mathrm{HV}$ monomer by the strain.

Effect of aeration on the P(3HB-co-3HV-co-4HB) terpolymer content and composition

Among the other factors which have significant impact on the biosynthesis of PHA, oxygen limitation was shown to affect PHA production under nitrogen limited conditions (Pozo et al. 2002). We have attempted to control the monomer compositions of $\mathrm{P}(3 \mathrm{HB}-\mathrm{co}-3 \mathrm{HV}-\mathrm{co}-4 \mathrm{HB})$ produced by $D$. acidovorans by regulating the oxygen transfer rate into the culture medium. The effect of aeration on the biosynthesis of $\mathrm{P}(3 \mathrm{HB}-\mathrm{co}-3 \mathrm{HV}-\mathrm{co}-4 \mathrm{HB})$ terpolymer has been tested by varying the agitation speed, as in Table 5 . The culture volume was kept
Table 4: Effect of different inoculum concentration on the biosynthesis of $\mathrm{P}(3 \mathrm{HB}-\mathrm{co}-3 \mathrm{HV}-\mathrm{co}-4 \mathrm{HB})$ by using $0.1 \%$ (wt/vol) sodium valerate and $0.9 \%$ (vol/vol) 1,4-butanediol ${ }^{\mathrm{a}}$

\begin{tabular}{|c|c|c|c|c|c|}
\hline \multirow{2}{*}{$\begin{array}{l}\text { Inoculum } \\
\text { concentration } \\
\% \text { (vol/vol) }\end{array}$} & \multirow{2}{*}{$\begin{array}{c}\text { Dry } \\
\text { cell } \\
\text { weight } \\
(\mathrm{g} / \mathrm{L})\end{array}$} & \multirow{2}{*}{$\begin{array}{c}\text { PHA } \\
\text { content }^{\text {b }} \\
\text { (wt\%) }\end{array}$} & \multicolumn{3}{|c|}{$\begin{array}{l}\text { PHA composition } \\
(\mathrm{mol} \%)\end{array}$} \\
\hline & & & $3 \mathrm{HB}$ & $3 \mathrm{HV}$ & $4 \mathrm{HB}$ \\
\hline 1 & 2.4 & 20 & 57 & 32 & 11 \\
\hline 2 & 2.5 & 25 & 46 & 34 & 20 \\
\hline 3 & 2.5 & 31 & 32 & 35 & 33 \\
\hline 4 & 2.6 & 29 & 32 & 34 & 34 \\
\hline 5 & 2.6 & 26 & 31 & 33 & 36 \\
\hline 6 & 2.7 & 24 & 30 & 33 & 37 \\
\hline 7 & 2.8 & 23 & 29 & 35 & 36 \\
\hline 8 & 2.8 & 24 & 30 & 32 & 38 \\
\hline 9 & 2.9 & 23 & 29 & 41 & 40 \\
\hline 10 & 3.0 & 20 & 28 & 32 & 40 \\
\hline
\end{tabular}

3HB, 3-hydroxybutyrate; 3-HV, 3-hydroxyvalerate; 4HB, 4hydroxybutyrate.

a Incubated for $48 \mathrm{~h}$ at $30^{\circ} \mathrm{C}$, initial $\mathrm{pH} 7.0$.

${ }^{b}$ PHA content in dry cells.

Table 5: Effect of agitation speed on the biosynthesis of $\mathrm{P}(3 \mathrm{HB}-\mathrm{co}-3 \mathrm{HV}-\mathrm{co}-4 \mathrm{HB})$ by using $0.1 \%(\mathrm{wt} / \mathrm{vol})$ sodium valerate and $0.9 \%(\mathrm{vol} / \mathrm{vol}) 1,4$-butanediol ${ }^{\mathrm{a}}$

\begin{tabular}{|c|c|c|c|c|c|}
\hline \multirow{2}{*}{$\begin{array}{l}\text { Agitation } \\
\text { speed } \\
(\mathrm{rpm})\end{array}$} & \multirow{2}{*}{$\begin{array}{l}\text { Dry cell } \\
\text { weight } \\
(\mathrm{g} / \mathrm{L})\end{array}$} & \multirow{2}{*}{$\begin{array}{l}\text { PHA } \\
\text { content }^{b} \\
(w t \%)\end{array}$} & \multirow{2}{*}{$\begin{array}{l}\begin{array}{l}\mathrm{PHA} \\
(\mathrm{mol} \%)\end{array} \\
3 \mathrm{HB}\end{array}$} & \multicolumn{2}{|c|}{ composition } \\
\hline & & & & $3 \mathrm{HV}$ & $4 \mathrm{HB}$ \\
\hline 50 & 2.1 & 17 & 3 & 50 & 47 \\
\hline 100 & 2.2 & 28 & 21 & 48 & 41 \\
\hline 150 & 2.5 & 31 & 32 & 35 & 33 \\
\hline 200 & 2.2 & 30 & 40 & 33 & 27 \\
\hline 250 & 2.2 & 31 & 54 & 30 & 16 \\
\hline
\end{tabular}

3HB, 3-hydroxybutyrate; 3-HV, 3-hydroxyvalerate; 4HB, 4hydroxybutyrate.

${ }^{a}$ Incubated for $48 \mathrm{~h}$ at $30^{\circ} \mathrm{C}$, initial $\mathrm{pH}$ 7.0.

${ }^{b} \mathrm{PHA}$ content in dry cells.

constant at $100 \mathrm{~mL}$ in $500 \mathrm{~mL}$ conical flasks. The increase of agitation speed was expected to increase the oxygen transfer rate which further enhances the amount of dissolved oxygen in each culture flask. The influence of agitation speed on PHA content was most intense from the speed of 50 to $150 \mathrm{rpm}$ whereby the PHA content was seen to increase from 17 to $31 \mathrm{wt} \%$ with the increasing agitation speed. Further increase in the agitation speed did not have any profound effect on the PHA content. Instead, the PHA content was kept constant at $31 \mathrm{wt} \%$. In this study, the molar fraction of $3 \mathrm{HB}$ increased sharply from 3 to $54 \%$ when the aeration rate was increased. This sudden increase in accumulation of $3 \mathrm{HB}$ monomer was responsible for the increase of $\mathrm{PHA}$ content. At first glance the $3 \mathrm{HV}$ and $4 \mathrm{HB}$ monomer might seem to decrease with the increase of agitation speed. However, the net effect on the accumulation of both monomers was not much. The increase of $3 \mathrm{HB}$ monomer content was responsible in bringing down the relative compositions of $3 \mathrm{HV}$ and $4 \mathrm{HB}$ monomers. It was observed that a limitation in oxygen transfer rate (lowered agitation speed) greatly improved the molar fractions of $3 \mathrm{HV}$ and $4 \mathrm{HB}$. It is 

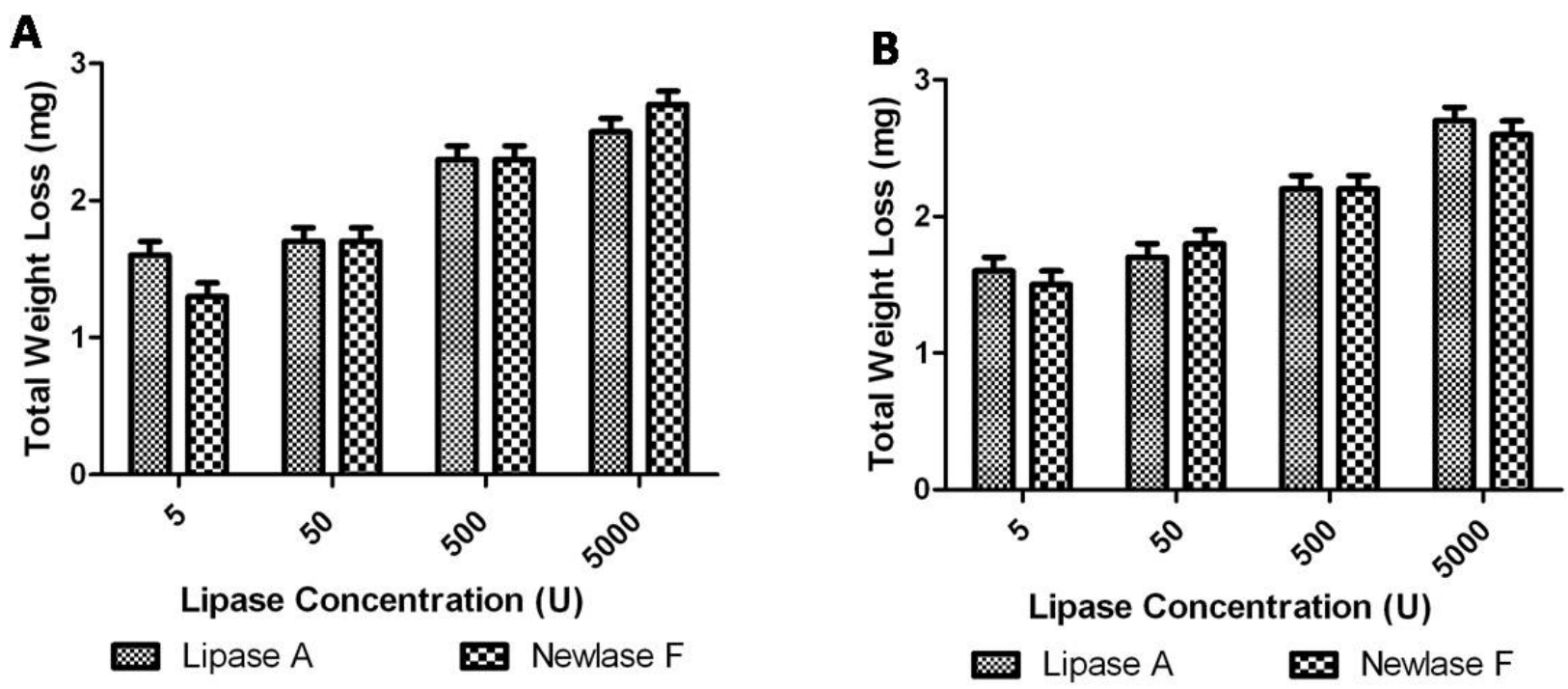

Figure 1: Total weight loss of $\mathrm{P}(3 \mathrm{HB}-\mathrm{co}-50 \mathrm{~mol} \%-4 \mathrm{HB})$ films after 7 days of degradation in aqueous solutions of lipases at $(\mathrm{A}) \mathrm{pH} 5$ and $(\mathrm{B}) \mathrm{pH} 7$.

interesting to note that the increase of agitation speed improves the composition of $4 \mathrm{HB}$ monomer in the production of $\mathrm{P}(3 \mathrm{HB}-\mathrm{co}-4 \mathrm{HB})$ by $D$. acidovorans (Lee et al. 2004). From the results obtained in this study it was observed that during the production of $\mathrm{P}(3 \mathrm{HB}-\mathrm{co}-3 \mathrm{HV}-\mathrm{co}-$ $4 \mathrm{HB})$ terpolymer by this strain, the increase in agitation speed aids in the incorporation of $3 \mathrm{HB}$ monomer instead. Therefore, by reducing the aeration rate to the culture medium, terpolymer with higher $3 \mathrm{HV}$ and $4 \mathrm{HB}$ monomers can be achieved. Another interesting observation was done by Ling et al (2011) while investigating the effect of dissolved oxygen on the production of poly(3hydroxybutyrate-co-3-hydroxy-4-methylvalerate) by Chromobacterium sp. USM2. It was found that the overall production of the copolymer was improved with the decrease of dissolved oxygen. The increase of $3 \mathrm{HB}$ monomer is the sole factor for the increase in PHA content, whereas there was negative effect on the incorporation of 3-hydroxy-4-methylvalerate monomer. In 1997, Hein and co-workers reported that supplementation of oxygen to culture medium was not favorable for the accumulation of $\mathrm{P}(4 \mathrm{HB})$ homopolymer. 3HB monomer was incorporated when culture volume was reduced (increase in oxygen transfer). The molar fraction of $3 \mathrm{HV}$ and $4 \mathrm{HB}$ does not solely depend on the concentrations of $4 \mathrm{HB}$ and $3 \mathrm{HV}$ precursors. Our results have shown that by controlling the oxygen transfer rate it is possible to control the monomer compositions of the resulted terpolymer.

\section{Enzymatic degradation of P(3HB-co-50 mol\%-4HB)}

4HB homopolymer and PHA copolymers with various $4 \mathrm{HB}$ monomer composition has been shown to be readily degradable by eukaryotic lipases (Vigneswari et al. 2009; Mukai et al. 1993). Besides being well proven with the ability to produce $4 \mathrm{HB}$-containing PHA with controlled compositions, the copolymer $\mathrm{P}(3 \mathrm{HB}-\mathrm{co}-50 \mathrm{~mol} \%-4 \mathrm{HB})$ produced by $D$. acidovorans was also shown to be biocompatible (Siew et al. 2007). As such, a study was conducted to evaluate factors that affect the rate of in vitro biodegradation of $\mathrm{P}(3 \mathrm{HB}-\mathrm{co}-50 \mathrm{~mol} \%-4 \mathrm{HB})$ film in the presence of eukaryotic lipases. The effect of $\mathrm{pH}$ and lipase concentrations on the erosion rate of polymer cast films were investigated by using lipases from Aspergillus niger (Lipase A "Amano" 12) and Rhizopus niveus (Newlase F). The reason for choosing these lipases as subject for study is because they are both proven to be able to degrade 4HB homopolymer (Mukai et al. 1993), but their ability to degrade $\mathrm{P}(3 \mathrm{HB}-\mathrm{co}-4 \mathrm{HB})$ copolymer was not much studied. Results collected in this study shows promising data of $\mathrm{P}(3 \mathrm{HB}-\mathrm{co}-50 \mathrm{~mol} \%-4 \mathrm{HB})$ degradation by both kinds of lipases. Figure 1 show the total weight loss of polymer films after 7 days of lipases degradation in various enzyme concentrations in $\mathrm{pH} 5$ and $\mathrm{pH} 7$ respectively. For both lipases, maximum weight losses of polymer films after seven days were about $50 \%$ of the original mass on day one. Studies have shown that lipases targeted specifically on $4 \mathrm{HB}$ monomers of $\mathrm{PHA}$ (Jaeger et al. 1995). It is of interest to note that at $\mathrm{pH} 5$, total weight loss caused by the lipase type of Newlase $F$ was higher than Lipase $\mathrm{A}$. While at $\mathrm{pH} 7$, Lipase A exerted more degradation on the polymer films than Newlase $F$. Although both types of lipases have the same active $\mathrm{pH}$ range of 5 to 8 , Lipase $A$ was shown to be more chemically reactive at $\mathrm{pH} 7$, while Newlase F was more reactive at $\mathrm{pH} 5$. This observation suggested that the copolymer is easily degradable by different types of lipases in a wide $\mathrm{pH}$ range and the maximum hydrolysis rate is achieved when the surrounding conditions support the optimum activity of the enzyme present. Both lipases have maintained their activity throughout the experiment and after seven days it can be observed that films incubated in enzyme solutions with the highest enzyme 
concentration $(5000 \mathrm{U})$ have resulted in the greatest weight loss if compared to the other lower concentrations of enzyme. The results obtained in this study have implied that $\mathrm{P}(3 \mathrm{HB}-\mathrm{co}-50 \mathrm{~mol} \%-4 \mathrm{HB})$ copolymer produced by $D$. acidovorans may be developed as a suitable material for the manufacturing of sutures and scaffolds for biomedical applications, since it is readily degraded by eukaryotic lipases at and around the physiological $\mathrm{pH}$. Further in vivo studies are necessary to determine the presence of sufficient concentrations of animal lipases with the ability to degrade this copolymer.

\section{CONCLUSION}

This study has demonstrated the possibility to control the monomer compositions of $\mathrm{P}(3 \mathrm{HB}-\mathrm{co}-3 \mathrm{HV}-\mathrm{co}-4 \mathrm{HB})$ produced by $D$. acidovorans through the balancing of physical and chemical parameters involved in the cultivation process. Since the strain was capable of producing high monomer compositions of $3 \mathrm{HV}$ and $4 \mathrm{HB}$, these advantages were successfully combined to produce controlled compositions of $\mathrm{P}(3 \mathrm{HB}-\mathrm{co}-3 \mathrm{HV}-\mathrm{co}-4 \mathrm{HB})$ terpolymer. In addition, the combination of 1,4-butanediol and sodium valerate as carbon sources was found to be most suitable for the mass production of controlled molar fractions of the terpolymer by this bacterial strain. $\mathrm{P}(3 \mathrm{HB}-$ co- $50 \%$ mol $4 \mathrm{HB}$ ) copolymer produced by $D$. acidovorans was also shown to be easily degradable by lipases with $50 \%$ weight loss after 7 days. Higher concentrations of lipase resulted in higher levels of biopolymer degradation. However, the rate of degradation was influenced by factors such as type of lipase, concentration of lipase solution and $\mathrm{pH}$. The overall results have shown that $D$. acidovorans is a very promising strain for the production of $4 \mathrm{HB}$ containing PHAs with specific compositions which are very suitable to be tailor made into biodegradable and biocompatible materials for medical applications.

\section{ACKNOWLEDGEMENTS}

The authors are grateful to Rong-Sheng Kee for his helpful contribution in this study. This work was supported by Incentive Grant provided by Universiti Sains Malaysia. The authors are indebted to Prof. Y. Doi (RIKEN Institute) for the kind gift of $D$. acidovorans for this study. D. H. E. Ch'ng would like to thank Universiti Sains Malaysia Fellowship for the financial support.

\section{REFERENCES}

Amirul, A. A., Syairah, S. N, Yahya, A. R. M., Azizan, M. N. M. and Majid, M. I. A. (2008). Synthesis of biodegradable polyesters by gram negative bacterium isolated from Malaysian environment. World Journal of Microbiology \& Biotechnology, 24 (8):1327-1332.

Braunegg, G., Sonnleitner, B. and Lafferty, R. M. (1978). A rapid gas chromatographic method for the determination of poly-b-hydroxybutyric acid in microbial biomass. European Journal of Microbiology and Biotechnology, 6:29-37.
Chanprateep, S. and Kulpreecha, S. (2006). Production and characterization of biodegradable terpolymer poly(3-hydroxybutyrate-co-3-hydroxyvalerate-co-4hydroxybutyrate) by Alcaligenes sp A-04. Journal of Bioscience and Bioengineering, 101 (1):51-56.

Hein, S., Sohling, B., Gottschalk, G. and Steinbuchel, A. (1997). Biosynthesis of poly(4-hydroxybutyric acid) by recombinant strains of Escherichia coli. FEMS Microbiology Letters, 153 (2):411-418.

Holmes, P. A. (1985). Applications of PHB - a microbially produced biodegradable thermoplastic. Physics in Technology 16 (1):32-36.

Jaeger, K. E., Steinbuchel, A. and Jendrossek, D. (1995). Substrate specificities of bacterial polyhydroxyalkanoate depolymerases and lipases bacterial lipases hydrolyze poly $(\omega$ hydroxyalkanoates). Applied and Environmental Microbiology, 61 (8):3113-3118.

Kimura, H., Yoshida, Y. and Doi, Y. (1992). Production of poly(3-hydroxybutyrate-co-4-hydroxybutyrate) by Pseudomonas acidovorans. Biotechnology Letters, $14(6): 445-450$.

Lee, W. H., Azizan, M. N. M. and Sudesh, K. (2004). Effect of culture conditions on the compositions of poly(3-hydroxybutyrate-co-4-hydroxybutyrate) synthesized by Comamonas acidovorans. Polymer Degradation and Stability, 84:129-134.

Lindenkamp, N., Peplinski, K., Volodina, E., Ehrenreich, A. and Steinbuchel, A. (2010). Impact of multiple $\beta$-ketothiolase deletion mutations in Ralstonia eutropha $\mathrm{H} 16$ on the composition of 3mercaptopropionic acid-containing copolymers. Applied and Environmental Microbiology 76 (16):5373-5382.

Ling, S. C., Tsuge, T. and Sudesh, K. (2011). Biosynthesis of novel polyhydroxyalkanoate containing 3-hydroxy-4-methylvalerate by Chromobacterium sp. USM2. Journal of Applied Microbiology, 111 (3):559-571.

Loo, C. Y. and Sudesh, K. (2007). Biosynthesis and native granule characteristics of poly(3hydroxybutyrate-co-3-hydroxyvalerate) in Delftia acidovorans. International Journal of Biological Macromolecules, 40:466-471.

Madden, L. A., Anderson, A. J., Asrar, J., Berger, P. and Garrett, P. (2000). Production and characterization of poly(3-hydroxybutyrate-co-3hydroxyvalerate-co-4-hydroxybutyrate) synthesized by Ralstonia eutropha in fed-batch cultures. Polymer, 41:3499-3505.

Martin, D. P. and Williams, S. F. (2003). Medical applications of poly-4-hydroxybutyrate: a strong flexible absorbable biomaterial. Biochemical Engineering Journal, 16 (2):97-105.

Mukai, K., Doi, Y., Sema, Y. and Tomita, K. (1993). Substrate specificities in hydrolysis of polyhydroxyalkanoates by microbial esterases. Biotechnology Letters, 15 (6):601-604.

Pozo, C., Martinez-Toledo, M. V., Rodelas, B. and Gonzalez-Lopez, J. (2002). Effects of culture 
conditions on the production of polyhydroxyalkanoates by Azotobacter chroococcum $\mathrm{H} 23$ in media containing a high concentration of alpechin (wastewater from olive oil mills) as primary carbon source. Journal of Biotechnology, 97 (2):125131.

Ramachandran, H., Iqbal, N. M., Sipaut, C. S. and Amirul, A. A. (2011). Biosynthesis and characterization of poly (3-hydroxybutyrate-co-3hydroxyvalerate-co-4-hydroxybutyrate) terpolymer with various monomer compositions by Cupriavidus sp. USMAA2-4. Applied Biochemistry and Biotechnology, 164 (6):867-877.

Saito, Y. and Doi, Y. (1994). Microbial synthesis and properties of poly(3-hydroxybutyrate-co-4hydroxybutyrate) in Comamonas acidovorans. International Journal of Biological Macromolecules, $16(2): 99-104$.

Saito, Y., Nakamura, S., Hiramitsu, M. and Doi, Y. (1996). Microbial synthesis and properties of poly(3hydroxybutyrate-co-4-hydroxybutyrate). Polymer International, 39 (3):169-174.

Siew, E. L., Rajab, N. F., Bin Osman, A., Sudesh, K. and Inayat-Hussain, S. H. (2009). Mutagenic and clastogenic characterization of poststerilized poly(3hydroxybutyrate-co-4-hydroxybutyrate) copolymer biosynthesized by Delftia acidovorans. Journal of Biomedical Materials Research Part A, 91A (3):786794.

Siew, E. L., Rajab, N. F., Osman, A. B., Sudesh, K. and Inayat-Hussain, S. H. (2007). In vitro biocompatibility evaluation of poly(3-hydroxybutyrate-co-4hydroxybutyrate) copolymer in fibroblast cells. Journal of Biomedical Materials Research Part A, 81 (2):317325.

Taidi, B., Anderson, A. J., Dawes, E. A. and Byrom, D. (1994). Effect of carbon source and concentration on the molecular mass of poly(3-hydroxybutyrate) produced by Methylobacterium extorquens and Alcaligenes eutrophus. Applied Microbiology and Biotechnology, 40 (6):786-790.

Vigneswari, S., Vijaya, S., Majid, M. I., Sudesh, K., Sipaut, C. S., Azizan, M. N. and Amirul, A. A. (2009). Enhanced production of poly(3hydroxybutyrate-co-4-hydroxybutyrate) copolymer with manipulated variables and its properties. Journal of Industrial Microbiology and Biotechnology, 36 (4):547-556.

Ying, T. H., Ishii, D., Mahara, A., Murakami, S., Yamaoka, T., Sudesh, K., Samian, R., Fujita, M., Maeda, M. and Iwata, T. (2008). Scaffolds from electrospun polyhydroxyalkanoate copolymers: fabrication, characterization, bioabsorption and tissue response. Biomaterials, 29 (10):1307-1317.

Zinn, M., Furrer, P. and Panke, S. (2007). Efficient recovery of low endotoxin medium-chain-length poly([R]-3-hydroxyalkanoate) from bacterial biomass. Journal of Microbiological Methods, 69 (1):206-213. 